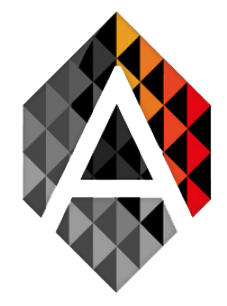

\title{
Integral Support Predictive Platform for Industry 4.0
}

\author{
Sergio Márquez-Sánchez ${ }^{\mathrm{a}}$, Jorge Herrera-Santosa, Mar- \\ ta Plaza-Hernandez ${ }^{\mathrm{a}}$, Eugenia Perez-Pons ${ }^{\mathrm{a}}$ and Juan M. \\ Corchado $^{\mathrm{a}, \mathrm{b}, \mathrm{c}, \mathrm{d}}$
}

${ }^{a}$ Research group in Bioinformatics, Intelligent Computer Systems and Educational Technology (BISITE), R\&B building, Calle Espejo s/n, 37008, Salamanca, Spain

b Air Institute, IoT Digital Innovation Hub (Spain), 37188, Salamanca, Spain

c Department of Electronics, Information and Communication, Faculty of Engineering, Osaka Institute of Technology, 535-8585 Osaka, Japan.

d Pusat Komputeran dan Informatik, Universiti Malaysia Kelantan, Karung Berkunci 36, Pengkaan Chepa, 16100

Kota Bharu, Kelantan, Malaysia smarquez@usal.es, jorgehsmp@usal.es, martaplaza@usal.es, eugenia.perez@usal.es,jm@corchado.net

$\begin{array}{ll}\text { KEYWORD } & \text { ABSTRACT } \\ \text { IIoT; Artificial } & \begin{array}{l}\text { Currently, companies in the industrial sector are focusing their efforts on } \\ \text { Intelligent; }\end{array} \\ \text { incorporating the advances contained in the Industry } 4.0 \text { model, to continue } \\ \text { Neural } \\ \text { Networks; Big } \\ \text { Data. } & \text { to productivity, have a remarkable impact on the working environment of } \\ & \text { for example, there are projects to develop augmented reality technologies for } \\ & \text { maintenance and industrial training, advanced modelling tools for additive } \\ & \text { manufacturing, or Big Data analysis platforms for industrial data. However, } \\ & \text { the solutions designed are too specific to a particular industry problem or the } \\ & \text { platforms proposed are too generalist and not easily adaptable to the industries. } \\ & \text { This work seeks to provide a reference software architecture at the service of } \\ & \text { the connected industry that allows the provision of new capacities for process } \\ & \text { optimisation, predictive maintenance and real-time visualisation, integrating } \\ \text { all the relevant information generated by the existing systems, incorporating } \\ \text { new sources of data resulting from the digital society, and ensuring future } \\ \text { compatibility with the new sources of information, solutions and Industrial } \\ \text { Internet of Things (IIoT) devices that may be implemented.The platform } \\ \text { provides a reduction of time and effort invested in extracting the necessary } \\ \text { information for the optimisation of the processes. }\end{array}$

Sergio Márquez-Sánchez, Jorge Herrera-Santos, Marta Plaza-Hernandez, Eugenia Perez-Pons and Juan M. Corchado Integral Support Predictive Platform for Industry 4.0
ADCAIJ: Advances in Distributed Computing and Artificial Intelligence Journal Regular Issue, Vol. 9 N. 4 (2020), 71-82 eISSN: 2255-2863 - https://adcaij.usal.es Ediciones Universidad de Salamanca - CC BY-NC-ND 


\section{Introduction}

In the industry, it is necessary to collect data from various sources in a reliable (Dong and Srivastava, 2013) and unified way, transforming them to obtain information that facilitates the scalability of the media, reducing development times and costs (Bokor, 2012). It is necessary to press attention to the security (Clifton et al., 2004) and quality (Lenzerini, 2002) of the data handled, which must be reflected in an action plan for the integration of data from heterogeneous sources. This plan has to include the evaluation of the added value of the source and the competitive advantage it provides, seeking to ensure that it results in the agility of the tasks for the efficient management of change processes. This information needs to be characterised, to integrate it into an intelligent tool, and considered from the design phase, allowing the development of ad-hoc methodologies that would enable the information to be exploited natively and all its value to be extracted.

The platform will implement a cognitive system through data integration techniques based on virtual organisations of agents (De la Prieta et al., 2013; Lozano et al., 2014). It can be fed from open and linked data sources, related to both aspects of production and others that can influence from the business point of view. This concept favours reuse, reduces redundancy, maximises connectivity and creates a process of extracting social knowledge about the industry (Villarrubia et al., 2014). Based on this structural design, the platform will interact transparently with Customer Relationship Management (CRM), Enterprise Resource Planning ERP, Month on Month (MOM), Electronic Data Interchange (EDI), Computerized Maintenance Management Systems (CMMS), etc. These systems consume and classify the information obtained, establishing an information management system based on the EDI standard.

Besides, it will incorporate other sources that provide real-time information on the processes themselves (low-cost IIoT devices, work reports, expert knowledge), which requires the definition of organisations specialised in Big Data for Industry 4.0. The incorporated information fusion algorithms (whether structured or unstructured) make it possible to build a knowledge base on which to innovate in solving problems, reducing costs or improving maintenance. In this field of information processing, the use of free use frameworks stands out, which make it possible to apply data mining processes and intelligent algorithms, in order to obtain data from different sources, to build a Smart Data system capable of providing smart responses.

This work will serve as a basis for the development of ad-hoc tools, that will allow the optimisation of production and industrial maintenance. Thus, the best methodology to be used is determined, and new knowledge extraction algorithms are proposed, based on the available information, centred on these objectives, which will serve as the basis for the scenario detection systems and the prediction and solution proposal modules. This concept is directly linked to the concept of information fusion, which summarises or aggregates data of a very diverse nature. Hence the importance of the capacity to convert information into a unit that can be handled by the system (Rodríguez et al., 2015) and that provides value. For this purpose, it will make use of neural networks, fuzzy logic, Bayesian networks, decision trees and other hybrid techniques of inference and artificial intelligence (Bajo et al., 2015), that will provide a summary view of the large volume of data from which information is to be obtained. In the article, these techniques will be included in a virtual organisation in charge of the fusion, which will make it possible to draw on data sources from multiple domains (energy, machines, climate, socio-economic). Linked to each other, this will facilitate carrying out more complete analyses, mainly useful in data mining processes, specifically in the discovery of knowledge.

Sergio Márquez-Sánchez, Jorge Herrera-Santos, Marta Plaza-Hernandez, Eugenia Perez-Pons and Juan M. Corchado

Integral Support Predictive Platform for Industry 4.0
ADCAIJ: Advances in Distributed Computing and Artificial Intelligence Journal Regular Issue, Vol. 9 N. 4 (2020), 71-82 elSSN: 2255-2863 - https://adcaij.usal.es Ediciones Universidad de Salamanca - CC BY-NC-ND 
The remaining part of this work is organized as follows. Section II describes an overview of the related literature. Section III details the system design. Finally, in the last section we present some conclusive remarks and directions of future work.

\section{Related Work}

Predictive maintenance involves the observation of industrial processes to discover common anomalies that lead to failures and being able to prevent them before they occur, as the cost of repairing a machine is usually much higher than the cost of maintenance itself. Every day there are more and more projects that showcase systems and solutions that advocate this type of strategy, with examples such as IBM's Freight Logistics Asset Management and Predictive Maintenance, the FP7 PLANTCockpit article (Puig Ramírez, 2010) or the Bosch IoT Suite, that integrate predictive maintenance solutions (Porter and Heppelmann, 2015), capturing data using sensors that monitor the machines, which maximise the availability of the machines involved in the industrial processes, increasing the efficiency of the maintenance process. The appearance of technologies such as Big Data has also favoured the processing of data in real-time, to which data mining techniques can be applied in largescale industrial processes (Yao et al., 2015). There are also proposals related to sectors like energy, such as the Tabón project which proposes different intelligent algorithms (Chamoso et al., 2016) for carrying out predictive maintenance in electrical distribution infrastructures. This project determines which components to review and the best time to do so, showing excellent efficiency, which translates into a very significant reduction in maintenance costs (Chamoso Santos et al., 2016).

Trying to advance in this field, we are going to introduce the design of an inference engine, which makes use of the CNNs and their potential for the treatment of variables in various dimensions: by capturing the vibrations of a motor, from which its frequency distribution is obtained (by transferring the samples from the time domain to the frequency domain, using the Fourier transform), a series of vibration maps will be constructed in which the frequency distribution of the vibration (harmonics) over time is contrasted (similar to the spectrograms of mel), so that we obtain a series of time windows with which to construct «heat maps». With these datasets, Convolutional Neural Network (CNNs) are trained, allowing the construction of filters (in which noise, temperature and other measured parameters are also crossed) that have the capacity to discover diverse problematic patterns and that at the same time allow approximating a situation based on the taking of data in real-time, making a prediction that places that sampled scenario, in a position within the map of incidences that can be tackled with preventive actions. This architecture builds a recommending module that, based on the wide knowledge base integrated by the cognitive system and applying Fault Tree Analysis (FTA) and Failure Mode and Effect Analysis (FMEA) analysis, allows you to offer a response for each anomaly or deviation detected and which can later be validated by an expert through what is known as Deep Reinforcement Learning (DRL).

This type of network is especially indicated for multidimensional variables. It allows the problem of lack of data in recommendation systems to be tackled in a solvent way: they do not need feedback or a previous model on a set of data, for comparison, because they are capable of detecting a deviation in the operating pattern and preparing a prediction with the set of parameters that they handle, allowing anomalies to be detected and the origin of the problem that generates them to be predicted, at the same time as offering original solutions to unpublished situations, by approximation to learned cases. Its operation has been demonstrated for use in the recommendation of Spotify playlists (Dieleman, 2014),

Sergio Márquez-Sánchez, Jorge Herrera-Santos, Marta Plaza-Hernandez, Eugenia Perez-Pons and Juan M. Corchado

Integral Support Predictive Platform for Industry 4.0
ADCAIJ: Advances in Distributed Computing and Artificial Intelligence Journal Regular Issue, Vol. 9 N. 4 (2020), 71-82 elSSN: 2255-2863 - https://adcaij.usal.es Ediciones Universidad de Salamanca - CC BY-NC-ND 
based on the characteristics of the music (Van den Oord et al., 2013), without previous user evaluations, which is why its application to predictive maintenance is an important innovation in this field.

The development of platforms to respond to different computing problems is a reasonably widespread solution.

One of the current trends is to develop a cloud-based architecture (Heras et al., 2012; De la Prieta et al., 2014) that allows large volumes of data to be processed, with the processing capacity adjusted to the needs of each moment. The majority of these solutions have similarities, with their architecture being transparent to the user, who from the outside perceives it as a set of services grouped into three fundamental pillars: software, platform and infrastructure. While internally, as we have already seen, this type of system behaves elastically and the technologies on which it is based have reached an advanced state of maturity: virtualisation, server farms/clusters, web services, web portals, etc. This architecture, combined with the design of virtual organisations of agents, makes it possible to modularise the platform and make it scalable, facilitating the addition of new vertical solutions that are integrated into the horizontal design of the platform.

One of the aspects on which the research work is focusing on the optimisation of processes is the application of numerical and graphic tools (Manan et al., 2009), as well as flexible computing and fuzzy logic Software Engineering (SWE) algorithms (Gabriel et al., 2016), to the parameters that have some impact on the consumption of resources. The use of this type of algorithm is based on the calculation of the weight of the factors, characterising them according to the different production scenarios that may occur and, based on them, immediately adapting the system. In this sense, one of the most important innovations is the use of data mining and time series algorithms to predict energy consumption, production rates and raw material costs (Wang et al., 2017). Still, significant research work is also being carried out on other new algorithms to predict market (Chen and Kuo, 2017) demand and water (Shang et al., 2017) and electricity consumption (Zhang et al., 2016). It is possible to develop a series of applications that incorporate resource management and planning algorithms in the Smart Factory environment in order to use the factory's resources (Canizes et al., 2017) at their optimum point of operation, minimise operating costs and maximise profits, taking into account the various limitations (stock breaks, planning based on energy costs, etc.). The aim is to seek the global optimisation of production, trying to maximise different efficiency indices, such as Overall Efficiency Equipment (OEE), where through planning, the aim is to increase the availability, the performance of the installations and the quality of the products. These factors depend on many variables, so their optimisation through autonomous and intelligent systems requires collecting information from the entire life cycle of a product, incorporating data that affect the supply of raw materials to the demand by end-users.

Edge computing and Smart Data technologies are derived from Cloud Computing and Big Data (Shi and Dustdar, 2016; Casado-Vara et al., 2018). They are the next step in the evolution of these technologies and represent an improvement in terms of proposing an environment capable of processing information at various levels (nodes-platform) more rationally and improving performance in terms of the use of resources and the quality of the data handled.

Similarly, the nodes can act autonomously, communicating with the platform promptly when their services are required. Also, it allows the introduction of security layers between the platform and the nodes, which increases the reliability of the data. All of this contributes to improving the quality of the information obtained, which, thanks to the complementary capacities provided by the platform (capacities for extracting and integrating information, capacity for learning to generate new rules, high capacity for processing raw data...), allows the system not only to process data but also to understand what the data it is handling means, in terms of the tasks it has to perform. These new trends are going

Sergio Márquez-Sánchez, Jorge Herrera-Santos, Marta Plaza-Hernandez, Eugenia Perez-Pons and Juan M. Corchado

Integral Support Predictive Platform for Industry 4.0
ADCAIJ: Advances in Distributed Computing and Artificial Intelligence Journal Regular Issue, Vol. 9 N. 4 (2020), 71-82 elSSN: 2255-2863 - https://adcaij.usal.es Ediciones Universidad de Salamanca - CC BY-NC-ND 
to revolutionise the concepts of Cloud Computing and Big Data, but there are currently no significant developments in this areas (Satyanarayanan, 2017).

The concept of Internet of Things (IoT) (Corchado, ) has become widespread in recent years and has reached out to the ordinary user. Within the set of elements included in consumer electronics, we can find versions of practically any type of device that implements these characteristics. This type of consumer goods, which have an added value, is an incentive for buyers and a hook for manufacturers, which has led to their rapid development. In the industrial sector, the benefits provided by equipment with these characteristics are even more significant. Still, as it is a not so massive market and requires relatively expensive technologies (special sensors for industrial environments, robust communication protocols, etc.), it has not taken off. This situation means that the supply of IIoT (Boyes et al., 2018) devices within the industry is limited to specialised capital goods manufacturers, with inflexible and high-cost solutions. In the same way, as other RD projects have brought this concept closer to other fields, this proposal aims to provide a versatile solution, adaptable to many industrial sectors, which will make it possible to offer IIoT capabilities to the systems already installed. In this way, progress can be made in the generalisation of this type of device to contribute to its dissemination and the reduction of its implementation cost, which will generate important advantages for industry as a sector.

Predictive maintenance (Mobley, 2002) is the archetype of maintenance management systems. The theory, based on the control of all the variables of a process, which allows an exact prediction of the probability of failure, is difficult to achieve. As we approach a natural process, the number of variables shoots up, and this calculation becomes unmanageable. Until now, processing capacity limitations have been the main handicap for obtaining acceptable solutions. Now, the needs for sensorisation (at a very high cost) and the design of a realistic model, are those that most affect the precision of these systems. This type of work aims to break the existing technological barrier, providing more accurate and economical solutions. To this end, instead of implementing expensive automation projects, which require a manual design by an engineering firm and a sensorisation plan following the guidelines set by a proposal, the aim is to design a more efficient and flexible process, based on data, which collects them in a massive way and allows a real model of an industry to be drawn up. This approach, together with the processing capacity of the Cloud-based platform, makes it possible to discover patterns that highlight certain relationships that, with a traditional solution to the problem, can go unnoticed. In this way, the solution approaches a purely predictive system, in which scenario simulation determines the probability of failure.

For its part, the problem of maintenance and safety at work in the industry has also been approached in various ways. Usually, in the case of the latter, the systems responsible for ensuring the safety of workers are designed by the company's existing risk prevention plans. Usually, they react to measured stimuli, provided that these reach a minimum threshold (action-reaction), which presents little capacity for adaptation or for modifying behaviour in the face of new situations. On the other hand, $\mathrm{AI}$ systems in which learning mechanisms are introduced base their approach on a series of rules that, combined with the stored knowledge obtained from solutions to known problems, try to predict the result of unpublished experiments. Even though, in specific environments, some techniques, such as neural networks, case-based reasoning systems and deep learning, have obtained good results. The use of hybrid neuro-symbolic algorithms (Riverola and Corchado, 2000) is proposed here, which combine several of these techniques and which will allow the system to determine whether a particular situation poses a risk, depending on certain boundary conditions (the normal operation of a machine can pose a risk for a worker under certain circumstances and these do not have to be static).

Sergio Márquez-Sánchez, Jorge Herrera-Santos, Marta Plaza-Hernandez, Eugenia Perez-Pons and Juan M. Corchado

Integral Support Predictive Platform for Industry 4.0
ADCAIJ: Advances in Distributed Computing and Artificial Intelligence Journal Regular Issue, Vol. 9 N. 4 (2020), 71-82 eISSN: 2255-2863 - https://adcaij.usal.es Ediciones Universidad de Salamanca - CC BY-NC-ND 
The social computing paradigm is now a trend in the design of computer systems for solving problems with a certain degree of complexity. These socio-technological tools require the use of artificial intelligence for the management of artificial communities, which provide these systems with the capacity to establish a significant relationship of collaboration between humans and machines, when it comes to solving the problems posed, from a social perspective. There are several examples of this technology (Chamoso et al., 2019; García et al., 2017), including the book recommendation system used by Amazon based on the opinions of other users with similar tastes to a specific user or another simpler one, as is the concept on which the CAPTCHA is based (Von Ahn et al., 2003).

\section{Methodology}

The integral platform proposed in this work seeks to unify a software architecture, connecting the industry with the capabilities to optimize processes, predictive maintenance and real-time visualization, integrating the information generated in the system and incorporating the information sources from Edge Computing IIoT devices and information sources from production and operators. The general objective of this work is to provide a reference software architecture at the service of the connected industry that will make it possible to provide new capacities for process optimisation, predictive maintenance and real-time visualisation, integrating all the relevant information generated by the existing systems, incorporating new sources of information resulting from the digital society, and ensuring future compatibility with the new sources of information, solutions and IIoT devices that may be implemented. It will be designed under the social computing paradigm and will integrate new AI algorithms and information fusion models, which allow the processing of large volumes of data, the extraction of relevant information, Smart Data.

The proposed solution integrates a Smart Data platform with functionality within a Fog/Edge Computing environment capable of processing and combining in real-time data from different sources such as ERP, MOM, CMMS, Supervisory Control and Data Acquisition (SCADA), IIoT, collecting information and measuring factory parameters such as vibrations, noise, etc. This capacity, combined with other technological innovations, such as cognitive systems, convolutional neural networks and deep reinforcement learning, makes it possible to build a tool capable of controlling an enormous set of parameters. These parameters could be collected of the processes and the environment, and of providing exhaustive knowledge of the situation of the productive means, incorporating intelligent mechanisms that help to optimise the operations, maintenance and security. The system also includes capacities to adapt to the changing conditions of the environment using real-time visualisation by the user with wearable, mobile or tablet devices, as well as visualisation and control from any computer warning of any anomaly that may occur in the system. The combination of the methods described allows the creation of a reference software architecture for the connected industry on which the different specific vertical solutions are deployed, guaranteeing the processing of large data sets. These include relevant information for the improvement of industrial Key Performance Indicator (KPIs) and OEE (process optimisation), the «smartisation» of maintenance systems (predictive maintenance) and visualisation using tablets, mobiles or wearable SmartWatch. The platform will include backward compatibility with existing systems and forward compatibility with new vertical solutions, data sources and future IIoT devices that can be deployed.

The solution is designed with modularity to adapt to the needs of the industry Figure1, both at the level of the processing capacity of new lines or increased data flow and at the level of scalability of

Sergio Márquez-Sánchez, Jorge Herrera-Santos, Marta Plaza-Hernandez, Eugenia Perez-Pons and Juan M. Corchado

Integral Support Predictive Platform for Industry 4.0
ADCAIJ: Advances in Distributed Computing and Artificial Intelligence Journal Regular Issue, Vol. 9 N. 4 (2020), 71-82 elSSN: 2255-2863 - https://adcaij.usal.es Ediciones Universidad de Salamanca - CC BY-NC-ND 
the solution, allowing the incorporation of new developments that use the capabilities of the platform. This modularity has a direct influence on the capacity to offer a reusable solution in environments with similar characteristics and also allows it to adapt to the constant changes that surround industrial installations, adapting itself to cover all needs without the need for costly changes or implementations.

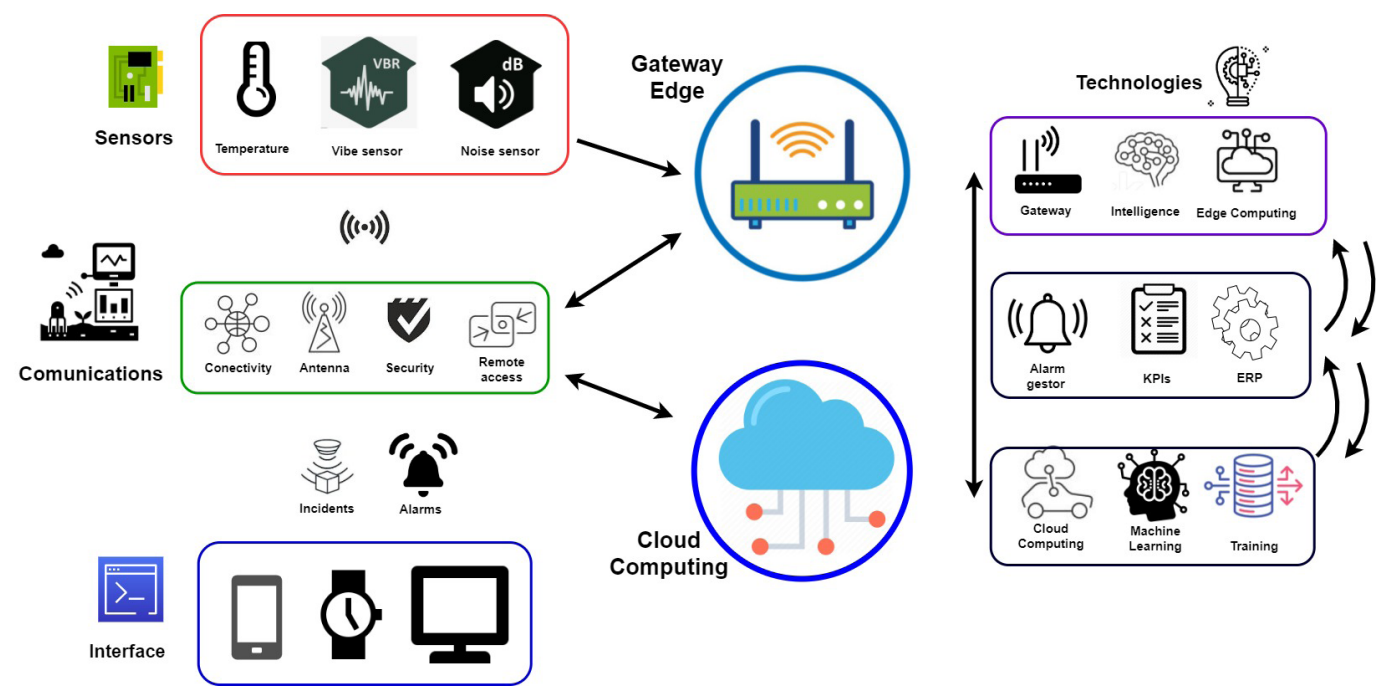

Figure 1: System architecture diagram.

The virtual organisations for process optimisation will allow not only the definition of the KPIs of the means in function of the entire life cycle of the product (incorporating information from suppliers, factory capacity, demand, energy costs, etc.) but also allow the grouping/breakdown of the planning, reaching the objectives set by shifts and monitoring the production ratio covered, analysing the causes of possible deviations and generating recommendations that allow the plan to be fulfilled. The virtual organisations of predictive maintenance will monitor different critical points that generate serious production problems related to the maintenance of the system (crossing records of the CMMS with work reports, analysing the performance of the machines, vibrations, temperature or noise level between others), seeking to eliminate the corrective actions, minimise the preventive ones and define a system that approaches a pure predictive system. This system will decompose the incidents and will analyse the causes of the failure (FTA), to learn these scenarios and avoid similar situations. In parallel, it will detect behaviours that do not fit the normal model and will try to predict what consequences (FMEA) they may cause in the system, incorporating a module for learning (Deep Reinforcement Learning) supported by experts (through Natural language processing (NLP)) and proposing actions to avoid a critical failure or a safety problem. Virtual security organisations will have a system capable of modelling the behaviour of industrial communication networks by using a network of nodes will make it possible to read and decide whether the traffic is passing through them. That implies building the model, elaborating a set of guidelines for the nodes to apply automatically, analysing the traffic in real-time and implementing Deep Reinforcement Learning techniques to validate the detected deviations.

This type of utility, deployed in a Cloud environment, ensures the flexibility and scalability of the solution, which can adapt to the real demand of the industry. This adaptability and capacity to evolve

Sergio Márquez-Sánchez, Jorge Herrera-Santos, Marta Plaza-Hernandez, Eugenia Perez-Pons and Juan M. Corchado Integral Support Predictive Platform for Industry 4.0
ADCAIJ: Advances in Distributed Computing and Artificial Intelligence Journal Regular Issue, Vol. 9 N. 4 (2020), 71-82 eISSN: 2255-2863 - https://adcaij.usal.es Ediciones Universidad de Salamanca - CC BY-NC-ND 
are key for the industrial sector and requires a certain amount of customisation to adapt the response to such a heterogeneous segment with so many particularities. In order to adequately evaluate the response of the system, the need to personalise the solution has been raised, developing an implementation to be able to accurately assess the improvement in the different aspects managed by the platform, such as performance analysis, cost savings, improvement in process time, reduction in maintenance stoppages, detection/protection against attacks through Information and communications technology (ICT) systems, etc. This action, which includes the development of different modules will not only provide a measure of the benefits offered by the final result of this work but will also provide a measure of the proposal's ability. Also it will be necessary to adapt and define a method for this process of integrating the platform with the different information management systems currently available to almost any type of industry.

In general, as shown in Figure2 the system consists of:

- The horizontal platform, which provides capacity for processing and managing information, generating security policies and integrating the vertical utilities/solutions that are to be incorporated.

- A set of vertical solutions that provide tools for the automated monitoring and improvement of different aspects within the industry.

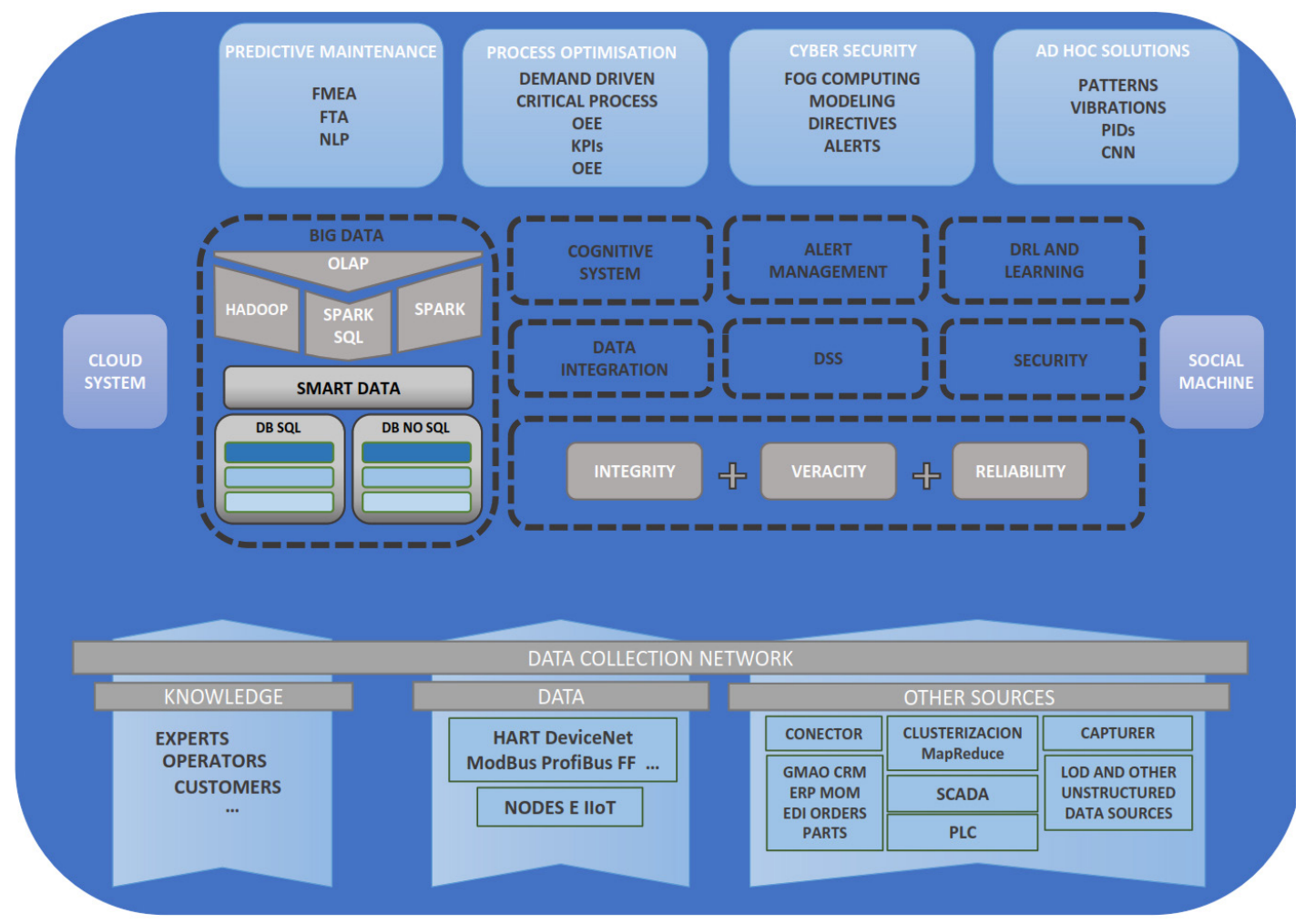

Figure 2: Software technologies and system components.

Sergio Márquez-Sánchez, Jorge Herrera-Santos, Marta Plaza-Hernandez, Eugenia Perez-Pons and Juan M. Corchado

Integral Support Predictive Platform for Industry 4.0
ADCAIJ: Advances in Distributed Computing and Artificial Intelligence Journal Regular Issue, Vol. 9 N. 4 (2020), 71-82 eISSN: 2255-2863 - https://adcaij.usal.es Ediciones Universidad de Salamanca - CC BY-NC-ND 
- A network of sensors that allows for the monitoring of different elements within the industrial environment by capturing certain parameters and allowing for a certain degree of operation, as well as the necessary means for communication with the platform (Gateway).

- Control panels and interfaces deployed in portable devices that allow users to interact with the information contained in the platform.

In order to achieve an optimal platform, it is necessary to integrate and develop various technological innovations, as well as to design new algorithms and techniques for the fusion of heterogeneous data that allow knowledge to be extracted from the data collected and the associated sensors. This approach, which ultimately seeks intelligent management of production and its optimisation in terms of maintenance, understood as a first step towards the excellence of predictive systems in itself already represents a major technological challenge. The challenges that are going to be faced concerning the current state of the art involve a series of advances that are also very relevant, in different fields. To cover these needs, the most widespread industrial standards will be analysed both at the level of communication in the industrial environment M2M (Machine to Machine) (Theoleyre and Pang, 2013) communication protocols (WirelessHART, ISA100, WiFi, ZigBee, 6LowPAN, OPC UA, LoraWan etc.).

\section{Conclusions}

The platform offer a variety of services that enable it to apply to different target audiences and this responds to the improvement of production standards and the increase of the General Efficiency of the Equipment (OEE), emphasising the quality control in early stages of the product and the improvement of the performance of the installations thanks to an adequate maintenance policy based on predictive systems. For this reason, this platform responds as a low-cost and fully customised Industry 4.0 solution. Among the competitive improvements, we can highlight the reduction of time and effort invested in extracting the necessary information for the optimisation of the processes. Decisions will be taken more quickly, in some cases automatically, and proactively, transforming the knowledge generated into concrete actions. Also, there will be a direct improvement in productivity, in the OEE, and the management of resources and raw materials. Some important aspects are the increase in security, tackling potential threats even before they become a real risk. On the other hand, the platform will be able to adapt and learn from its actions and face new challenges through unprecedented solutions to planning and maintenance problems.

It is proposed as future work the implementation of the platform. In this work, the system has been seen from a theoretical point of view, so it is proposed to develop the system in an industrial environment with the aim of having the simulation of events ant that can represent the possible behaviour patterns to check if all the developed modules work correctly or not (intelligent sensors and meters, intelligent control, automation, social media data collection, consumption analysis, personalized recommendations, etc.). Hybrid artificial intelligence algorithms will be integrated and agents will be designed to trigger alerts when security/maintenance problems are detected based on collected data, previous experiences (reasoning based on CBR cases) and expert data (mix of experts). All these applications bring an economic benefit to get companies to differentiate themselves from the competence.

Sergio Márquez-Sánchez, Jorge Herrera-Santos, Marta Plaza-Hernandez, Eugenia Perez-Pons and Juan M. Corchado Integral Support Predictive Platform for Industry 4.0
ADCAIJ: Advances in Distributed Computing and Artificial Intelligence Journal Regular Issue, Vol. 9 N. 4 (2020), 71-82 eISSN: 2255-2863 - https://adcaij.usal.es Ediciones Universidad de Salamanca - CC BY-NC-ND 


\section{Acknowledgments}

This work was supported by the European Regional Development Fund (FEDER). Project: DIGITEC Intelligent growth at the cross-border through specialisation of the business fabric in advanced digital technologies and blockchain. 0631 DIGITEC 3E

\section{References}

Bajo, J., De Paz, J. F., Villarrubia, G., and Corchado, J. M., 2015. Self-organizing architecture for information fusion in distributed sensor networks. International Journal of Distributed Sensor Networks, 11(3):231073. Bokor, Z., 2012. Integrating logistics cost calculation into production costing. Acta Polytechnica Hungarica, 9(3):163-181.

Boyes, H., Hallaq, B., Cunningham, J., and Watson, T., 2018. The industrial internet of things (IIoT): An analysis framework. Computers in industry, 101:1-12.

Canizes, B., Pinto, T., Soares, J., Vale, Z., Chamoso, P., and Santos, D., 2017. Smart city: A GECADBISITE energy management case study. In International Conference on Practical Applications of Agents and Multi-Agent Systems, pages 92-100. Springer.

Casado-Vara, R., de la Prieta, F., Prieto, J., and Corchado, J. M., 2018. Blockchain framework for IoT data quality via edge computing. In Proceedings of the 1st Workshop on Blockchain-enabled Networked Sensor Systems, pages 19-24.

Chamoso, P., De Paz, J. F., Bajo, J., and Villarrubia, G., 2016. Intelligent control of energy distribution networks. In International Conference on Practical Applications of Agents and Multi-Agent Systems, pages 99-107. Springer.

Chamoso, P., González-Briones, A., Rivas, A., De La Prieta, F., and Corchado, J. M., 2019. Social computing in currency exchange. Knowledge and Information Systems, 61(2):733-753.

Chamoso Santos, P., Prieta Pintado, F. d. 1., Paz Santana, J. F. d., Bajo Pérez, J., Corchado Rodríguez, J. M. et al., 2016. Agreement Technologies Applied to Transmission Towers Maintenance.

Chen, Z.-Y. and Kuo, R., 2017. Evolutionary algorithm-based radial basis function neural network training for industrial personal computer sales forecasting. Computational Intelligence, 33(1):56-76.

Clifton, C., Kantarciog`lu, M., Doan, A., Schadow, G., Vaidya, J., Elmagarmid, A., and Suciu, D., 2004. Privacy- preserving data integration and sharing. In Proceedings of the 9th ACM SIGMOD workshop on Research issues in data mining and knowledge discovery, pages 19-26.

Corchado, J. M. Blockchain and its applications on Edge Computing, Industry 4.0, IOT and Smart Cities. Dieleman, S., 2014. Recommending music on Spotify with deep learning. Sander Dieleman.

Dong, X. L. and Srivastava, D., 2013. Big data integration. In 2013 IEEE 29th international conference on data engineering (ICDE), pages 1245-1248. IEEE.

Gabriel, K. J., El-Halwagi, M. M., and Linke, P., 2016. Optimization across the water-energy nexus for integrating heat, power, and water for industrial processes, coupled with hybrid thermal-membrane desalination. Industrial \& Engineering Chemistry Research, 55(12):3442-3466.

García, Ó., Alonso, R. S., Prieto, J., and Corchado, J. M., 2017. Energy efficiency in public buildings through context-aware social computing. Sensors, 17(4):826.

Sergio Márquez-Sánchez, Jorge Herrera-Santos, Marta Plaza-Hernandez, Eugenia Perez-Pons and Juan M. Corchado

Integral Support Predictive Platform for Industry 4.0
ADCAIJ: Advances in Distributed Computing and Artificial Intelligence Journal Regular Issue, Vol. 9 N. 4 (2020), 71-82 elSSN: 2255-2863 - https://adcaij.usal.es Ediciones Universidad de Salamanca - CC BY-NC-ND 
Heras, S., De la Prieta, F., Julian, V., Rodríguez, S., Botti, V., Bajo, J., and Corchado, J. M., 2012. Agreement technologies and their use in cloud computing environments. Progress in Artificial Intelligence, 1(4):277-290.

Lenzerini, M., 2002. Data integration: A theoretical perspective. In Proceedings of the twenty-first ACM SIGMOD-SIGACT-SIGART symposium on Principles of database systems, pages 233-246.

Lozano, Á., Gil, A. B., and Li, T., 2014. Integration of Different ERP Systems on Mobile Devices. In Trends in Practical Applications of Heterogeneous Multi-agent Systems. The PAAMS Collection, pages 27-35. Springer.

Manan, Z. A., Tea, S. Y., and Alwi, S. R. W., 2009. A new technique for simultaneous water and energy minimisation in process plant. Chemical Engineering Research and Design, 87(11):1509-1519.

Mobley, R. K., 2002. An introduction to predictive maintenance. Elsevier.

Van den Oord, A., Dieleman, S., and Schrauwen, B., 2013. Deep content-based music recommendation. Advances in neural information processing systems, 26:2643-2651.

Porter, M. E. and Heppelmann, J. E., 2015. How smart, connected products are transforming companies. Harvard business review, 93(10):96-114.

Prieta, F. de la, Gil, A. B., Rodríguez-González, S., and Corchado, J. M., 2014. Cloud Computing and Multi Agent System to improve Learning Object Paradigm. IxD\&A, 23:38-49.

Prieta, F. de la, Rodríguez, S., Bajo, J., and Batista, V. F. L., 2013. Data integration in Cloud Computing environment. In Fourth International Workshop on Knowledge Discovery, Knowledge Management and Decision Support. Atlantis Press.

Puig Ramírez, J., 2010. Asset optimization and predictive maintenance in discrete manufacturing industry. Riverola, F. F. and Corchado, J. M., 2000. Sistemas híbridos neuro-simbólicos: una revisión. Inteligencia Artificial. Revista Iberoamericana de Inteligencia Artificial, 4(11):12-26.

Rodríguez, S., De Paz, J. F., Villarrubia, G., Zato, C., Bajo, J., and Corchado, J. M., 2015. Multi-agent information fusion system to manage data from a WSN in a residential home. Information Fusion, 23:43-57.

Satyanarayanan, M., 2017. The emergence of edge computing. Computer, 50(1):30-39.

Shang, Y., Lu, S., Gong, J., Shang, L., Li, X., Wei, Y., and Shi, H., 2017. Hierarchical prediction of industrial water demand based on refined Laspeyres decomposition analysis. Water Science and Technology, 76(11):2876-2887.

Shi, W. and Dustdar, S., 2016. The promise of edge computing. Computer, 49(5):78-81.

Theoleyre, F. and Pang, A.-C., 2013. Internet of Things and M2M Communications. River Publishers. Villarrubia, G., De Paz, J. F., Bajo, J., and Demazeau, Y., 2014. Context-Aware Module for Social Computing Environments. In Ambient Intelligence-Software and Applications, pages 183-191. Springer.

Von Ahn, L., Blum, M., Hopper, N. J., and Langford, J., 2003. CAPTCHA: Using hard AI problems for security. In International conference on the theory and applications of cryptographic techniques, pages 294-311. Springer.

Wang, D., Luo, H., Grunder, O., Lin, Y., and Guo, H., 2017. Multi-step ahead electricity price forecasting using a hybrid model based on two-layer decomposition technique and BP neural network optimized by firefly algorithm. Applied Energy, 190:390-407.

Sergio Márquez-Sánchez, Jorge Herrera-Santos, Marta Plaza-Hernandez, Eugenia Perez-Pons and Juan M. Corchado

Integral Support Predictive Platform for Industry 4.0
ADCAIJ: Advances in Distributed Computing and Artificial Intelligence Journal Regular Issue, Vol. 9 N. 4 (2020), 71-82 eISSN: 2255-2863 - https://adcaij.usal.es Ediciones Universidad de Salamanca - CC BY-NC-ND 
Yao, B., Zhou, Z., Xu, W., Fang, Y., Shao, L., Wang, Q., and Liu, A., 2015. Service-oriented predictive maintenance for large scale machines based on perception big data. In International Manufacturing Science and Engineering Conference, volume 56833, page V002T04A015. American Society of Mechanical Engineers.

Zhang, X., Hug, G., Kolter, J. Z., and Harjunkoski, I., 2016. Model predictive control of industrial loads and energy storage for demand response. In 2016 IEEE Power and Energy Society General Meeting (PESGM), pages 1-5. IEEE.

Sergio Márquez-Sánchez, Jorge Herrera-Santos, Marta Plaza-Hernandez, Eugenia Perez-Pons and Juan M. Corchado

Integral Support Predictive Platform for Industry 4.0
ADCAIJ: Advances in Distributed Computing and Artificial Intelligence Journal Regular Issue, Vol. 9 N. 4 (2020), 71-82 eISSN: 2255-2863 - https://adcaij.usal.es Ediciones Universidad de Salamanca - CC BY-NC-ND 